\title{
Pre-service EFL Teachers' Expectations, Needs, and Challenges in a Language Learning and Technology Course
}

\author{
Munassir Alhamami \\ English Department, Faculty of Languages and Translation, King Khalid University, Abha, Saudi Arabia \\ Hassan Costello \\ English Department, Faculty of Languages and Translation, King Khalid University, Abha, Saudi Arabia
}

\begin{abstract}
This study contributes to and expands the existing body of knowledge on the subject by examining the needs, expectations, and challenged by pre-service English as a foreign language (EFL) teachers in a language learning and technology (LL\&T) course. This study was conducted in a Bachelor of Arts program at a Saudi university. Research results are based on a qualitative survey utilising openended questions. The purposes of the questionnaire were to explore instructor: Expectations, needs, experiences, preferred technology, challenges, and suggestions. The survey sample size was 79 pre-service EFL teachers, and the survey period spanned two consecutive semesters. The results of the research indicate that each of the foregoing are important factors in the quality of technology-based pre-service EFL teachers training courses. See supra. The study also suggests that several important issues might easily be overlooked in course syllabus development and material usage.
\end{abstract}

Index Terms - language learning and technology, pre-service teacher perspectives, EFL teacher education, educational technology course, language teaching with technology

\section{INTRODUCTION}

The subject of this paper is language learning and technology (LL\&T) as it is related to EFL pre-service teachers in a Saudi university. This course introduces the pre-service teachers to educating EFL students using various forms of technology. Although many articles have been published in the field of LL\&T, most of the studies involve language learning survey participants that are currently enrolled in traditional English language classes. That is the students are in a traditional classroom with a live teacher or instructor. These studies can be classified into three types: 1. Effectiveness (The effects of technologies on language learner linguistic achievement), 2. Attitude (Language student attitudes toward technologies), and 3. Functions (How technologies can assist the teaching processes) (Alhamami, 2018).

As shown above, the number of categories in relevant studies is quite limited. There are a plethora of technologically based language learning courses for language students. However, there is a dearth of courses that use modern technologies designed for the express purpose of training pre-service teachers in LL\&T. The empirical evidence indicates that most EFL teacher training in this discipline is either ad hoc or self-taught.

Unsurprisingly, there is a limited supply of academic research available on the subject. It is unclear whether the lack of studies is a primary cause of the dearth of research material available or vice versa. Perhaps it is a matter of mixed causation; we can only speculate at this point. Irrespective of the correlation/causation dichotomy, one issue remains patent and manifest - EFL pre-service teachers who are taking the LL\&T course generally need guidance and assistance in developing course materials and conducting successful classes and training sessions for their future students. In determining how to best serve these needs, the authors herein have solicited information and feedback from 79 pre-service EFL teachers. This feedback was in the form of an open-ended questionnaire that was solicited over the course of two semesters.

\section{LITERATURE REVIEW}

We have already established that special courses about LL\&T should be included in the training and development of pre-service EFL teachers-in-training. The fundamental purposes of such courses are to raise awareness about the necessity of integrating modern technologies in language classrooms and assisting pre-service teachers in becoming proficient with said technologies. Koçoğlu (2009) examined the technological pedagogical content knowledge (TPCK) in pre-service EFL teachers enrolled in the computer-assisted LL\&T course in Turkey. The author also found that participants developed TPCK in various areas. They included the degrees to which 
teachers understood the technologies and their applications to language learners, knowledge of instructional strategies, knowledge of student learning methods, and technology and materials integration into coursework.

In an empirical study from China, Dong, Chai, Sang, Koh, and Tsai (2015) used TPCK as a theoretical framework to survey 390 pre-service teachers and 394 in-service teachers including the seven factors of TPCK. Based on the study, they found that there is a statistically significant difference between pre-service and in-service teachers in their levels of knowledge and confidence in the subject matter. The in-service teachers are generally more competent and confident than the pre-service teachers.

The development of an effective pre-service teacher course first requires a careful and competent analysis of learner needs. Courses that do not adequately meet learner needs and expectations unsurprisingly fail to produce favourable outcomes (Long, 2005). Learner needs and expectations should always be issues that are at the top of the mental awareness of course curriculum designers and syllabus writers. The limited research available does at least show a correlation between good pre-service training programs and in-service educational success. Satar and Akcan (2018) investigated the participation, interaction patterns, and social presence levels of pre-service EFL teachers in online communication. They found that online course tutoring skills and social presence improve preservice EFL teacher online participation skills. In addition, the pre-service coursework correlated with continuous improvement and increased participation in EFL learning.

As with any developing technology, learner/user attitude towards that technology has a big impact on its acceptance. Oftentimes, potential users of new instructional technologies are sceptical and/or fearful of new teaching tools and methods. Understanding the prevailing pre-service teacher attitudes toward technologies can help manage expectations, alleviate anxieties, and promote an active learning environment. Baföz (2016) explored pre-service EFL teacher attitudes toward language learning through social media. The researcher distributed a questionnaire among 120 pre-service EFL teachers in a Turkish university. The study concluded that social media could be an effective means for language learning. Presumably, pre-service teachers are accepting of using social media as a teaching tool because most are already users of social media platforms and are comfortable with the technology.

Yüksel and Kavanoz (2011) investigated the attitudes of 200 pre-service EFL teachers toward technology. They utilised a twelve-item, five-point Likert scale questionnaire in a Turkish university. The survey explored attitudes toward instructional technologies based on two independent variables - academic background and gender. The study concluded that male participants have a more positive attitude toward using technology than their female counterparts. Also, the study did not show a statistically significant difference in results based on university type and subject matter.

Currently, there is no uniformity between pre-service teacher training programs and the actual technologies implemented among many different language schools. Merc (2015) distributed a questionnaire among 86 preservice EFL teachers in Turkey and conducted 12 interviews with selected participants. The researcher found that many schools were not sufficiently prepared for a technologically based pre-service EFL teacher curriculum. Some schools simply did not have access to technology. Also in many cases, pre-service EFL teaching training was deficient. Zyad (2016) echoed Merc's findings. Zyad found that many middle and secondary school educators in Morocco have limited access to the technologies in the classroom. In addition, the researcher found that implementation of the use of education technologies was inconsistent in scope and purpose.

Another important factor in implementing technology-based education is user experience with instructional technologies. Firat and Serpil (2017) investigated the Internet use of 789 distance and on-campus pre-service teachers of language and other disciplines. The study concluded that pre-service foreign language teachers exhibit a moderate level of information and communication technology usage in comparison to other similarly situated teaching groups not in language-related fields.

\section{Statement of the Issues AND ReSEARCh Questions}

\section{A. Issues}

A review of the existing research indicates that previous studies cannot be considered as conclusive because they do not address the underlying pre-service EFL teacher beliefs about technology integration into LL\&T coursework. See Literature Review Section, supra. This conclusion is well-founded notwithstanding the limited availability of published research on the subject. See Id., Introduction Section, supra. Of note, a survey of a wide variety of existing Bachelor of Arts programs shows that there is a minimal number of LL\&T course offered to pre-service EFL instructors.

Most of the existing research, by and large, is from China and Turkey. These issues have not been explored by and within the Kingdom of Saudi Arabia - until now. Of course, competent research on the subject will be both relevant and valuable to educational institutions within the Kingdom. In addition, the international community will greatly benefit from perspectives in Saudi Arabia.

Again the amount of research material currently available is limited. See, Introduction Section, supra. It is also worth noting that most of the existing studies are quantitative in nature. While helpful, it would be most valuable to 
analyse qualitative results. As such, this study will employ and focus on open-ended questions allowing for detailed, expressive responses.

A penultimate issue is the current applicability of the scant existing research. Technology, especially in relation to computer-assisted language learning, develops at a breakneck pace. The speed of development has far exceeded the academic community's research and understanding of the issues concerning technology learning. Also, preservice EFL instructor attitudes and beliefs towards technology have likely evolved over time. This is especially significant given the rise of social media as a means of communication and learning over the last several years. As such, much of the data is stale and of unknown value in the current environment. That being said, one of the purposes of this study is to explore the issues given the technological developments occurring since the publication of the existing materials.

\section{B. Research Questions}

Q1. What are the expectations of pre-service EFL teachers in the LL\&T course?

Q2. What are the needs of pre-service EFL teachers in the LL\&T course?

Q3. What are the experiences of pre-service teachers in learning languages using technology?

Q4. What technologies do pre-service teachers prefer to use?

Q5. What are the challenges that pre-service EFL teachers in the LL\&T course?

Q6. What do pre-service EFL teachers suggest to improve LL\&T courses?

\section{Methodology}

\section{A. Context}

The study was conducted in a Bachelor of Arts in English program at a public university in Saudi Arabia. The medium of instruction was English. The program was designed to teach students English language skills in the first two years. They include: EFL Reading I, II, and III; EFL Writing I, II, and III; EFL Listening and Speaking I, II, and III; EFL Grammar I, II, and III; EFL Vocabulary Building I and II; and Study Skills. During the next two years, students take courses in four disciplines: Theoretical Linguistics, Applied Linguistics, Literature, and ArabicEnglish Translation. Students study a variety of subjects including: Syntax, Morphology, Phonetics, Phonology, Applied Linguistics I and II, LL\&T, Drama, Novel, Short Story, Poetry, and Translation I, II, and III. All of the courses in the plan are core courses, and no optional paths or tracks are available. The instructors are from different countries and have various academic backgrounds. The instructors range in rank from teaching assistant to full professor based on qualifications and experience.

\section{B. Instruments}

Data collection involved an open-ended questionnaire in order to glean qualitative survey results to expand upon prior research that was more quantitative in nature. The questionnaire consisted of six questions, each of which focused on a particular research subject. The first question concerned each participant expectations about the LL\&T course. The second question addressed each respondent's needs in an LL\&T course. The third question asked each respondent to detail their experiences in technology and language learning. The fourth question asked respondents to state their preferred technologies to learn and teach in the classroom. The fifth question asked participants to elucidate as to specific challenges they have faced and might face in LL\&T courses. The final question asked the respondents for suggestions on ways to improve the LL\&T course for EFL learners and expectations for EFL teachers. Appendix A shows the questions in Arabic and the English translation.

\section{Procedural History}

The researchers designed the questionnaire in Arabic because it is the native language of the participants. This allowed the participants to fully express their opinions without the added complication of utilizing a non-native language. The researchers distributed the questionnaire to all students enrolled in LL\&T during the summer semester. The researchers analyzed the participant responses and concluded that the questionnaire could be improved.

Subsequently, the researchers modified the questionnaire based on the initial responses and re-distributed the modified survey in the fall of that same year. The modifications were not substantive; some of the question language was clarified to elicit as detailed responses as possible.

It is worth noting that the authors took great care to ensure that standard ethical procedures were followed at all times. On numerous occasions, the participants were reminded that their involvement was strictly voluntary and that they would suffer no adverse consequences for failing to participate. They were also repeatedly advised that they could withdraw from the study at any time with or without cause. Participants were also guaranteed anonymity so that they could express their views and opinions freely.

\section{Participant Overview}


The study plan mandates that students take the LL\&T course in their sixth semester out of eight total semesters. Therefore, these students are well on their way towards earning their degrees in English. All of the subject students are native Arabic speakers, and the group is comprised mainly of Saudi nationals. At this level in the course of study, students are expected to be near fluent in the target language.

In the LL\&T course, there were separate sections averaging 32 students per class. The questionnaire was distributed to every student in each sections. The response rate to the survey was high. However, some students did not complete the questionnaire due to absence or the student voluntary dropping the class. A total of 79 pre-service EFL teacher-students successfully completed the questionnaire over the course of two semesters.

\section{ANALYSIS AND RESUltS}

The research was compiled and rigorously analysed. Participant responses were reviewed several times for clarity and internal consistency. Each line was then assigned a discreet code. Individual codes were then grouped into research focus areas. The code groups and individual data points were then correlated into major factors affecting pre-service EFL teacher training. This analysis procedure enabled the researchers to label and connect concepts, and from this, identify the major factors reviewed in detail later in this study. The following section presents the results that are classified into six major categories.

\section{A. First Category: Expectations of Pre-service EFL Instructors in the LL\&T Course}

After the coded factors in the first question were analyzed, two major themes emerged. The first theme is referred to as 'expected to know'. This relates to certain expectations related to subject knowledge. These include: Vocabulary words and terms related to technology, the advantages and disadvantages of technology and language learning, the importance of technology and education, the history of instructional technology, and the appropriate and effective use of technology. The participants overwhelmingly responded that each of the foregoing is important to know in the LL\&T environment.

The second theme is referred to as 'application'. This concerns a variety of expectations including: Using different online and other technologies in learning management systems, knowing different teaching methods using technologies, understanding and utilizing effective communication techniques in online language education, strategies for procuring additional instructional technologies that can be used in the classroom, and simplifying the use of technologies for language learners and teachers. Figure 1 shows that this respondent anticipated that the course would be more theoretical in nature and discusses the advantages and disadvantages of using technology in EFL classrooms.

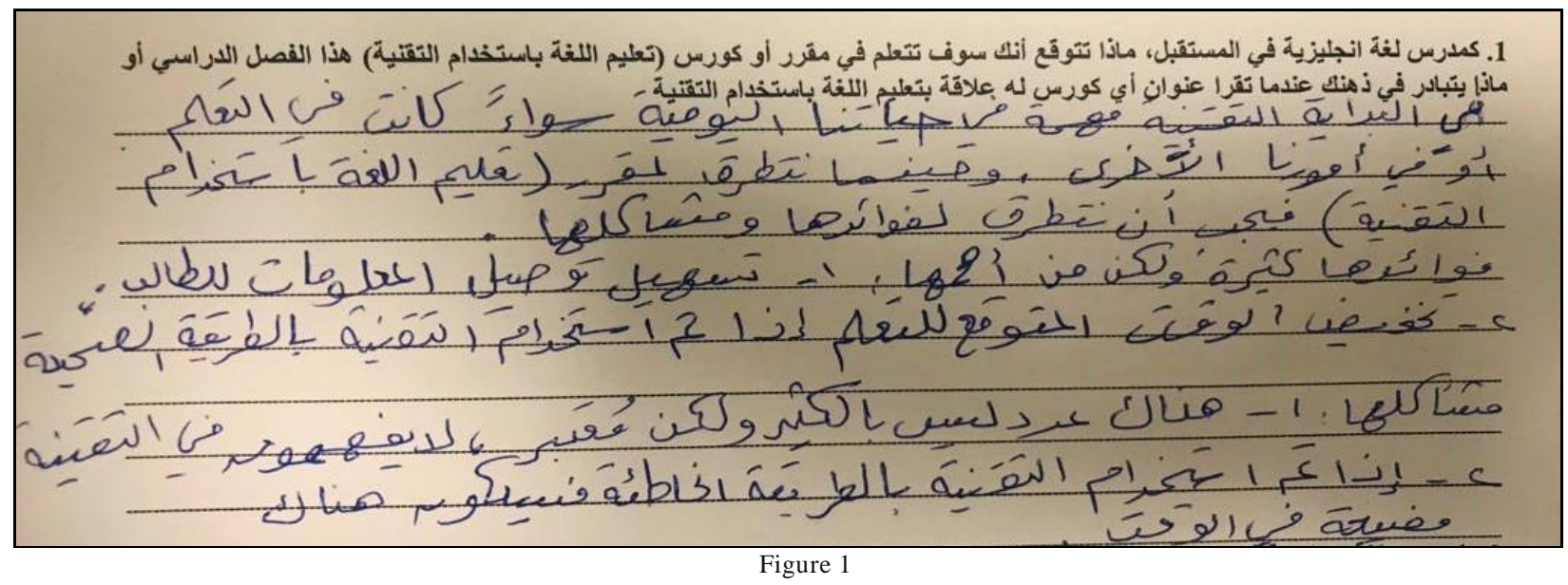

\section{B. Second Category: Needs of Pre-service EFL Instructors in the LL\&T Course}

The second category deals with the needs of the language teachers in EFL courses that use technology. These needs can be organized into three distinct classes: Knowledge, motivation, and application. Each of these classifications involves several factors that are discussed in detail below.

"Knowledge" refers to the pre-service EFL teachers' proficiency in the target language and accompanied technologies. These can be further described using four discreet factors. First, is the need for the instructor to be well-versed in all aspects of the target language including listening, reading, speaking, and writing. The second factor is the need for the teacher to thoroughly understand the advantages, disadvantages, capabilities, and limitations of the various instructional technologies. The third factor is the requirement for the instructor to have a working knowledge of the history of technological developments in education. This will have predictive value as the technology changes and evolves. The final factor is the teacher's ability to stay current with technological developments and the latest teaching methods. 
"Motivation", as referred to in this paper, involves the pre-service EFL teachers' enthusiasm for teaching and further professional development using technology. Again, there are several related factors. The first of which is that a teacher must have a genuine passion for the target language. Students can always tell whether a teacher is earnestly excited about the material. Zeal for the language will ensure a more productive learning environment. Next, a teacher must be competent and confident with respect to the use of the technologies employed in the classroom. Inability to use the technology seamlessly leads to confusion and frustration for both the teacher and student.

"Application" refers to the teachers' ability to marry prowess in the language with the ability to work the technology so that the students actually benefit from the teacher's efforts. First, instructors must become efficient in the use of technologies available in the classroom. For instance, if iPads are used in the class, the instructor should be very comfortable navigating through the different functions, programs, and applications. See Figure 2 showing one participant's comments regarding this issue, infra. Another factor involves problem-solving. That is, teachers must have a practical as well as theoretical knowledge about the workings of the various instructional technologies. This will permit smooth instruction and also enable teachers to help any students struggling with the technologies. As such, another important factor is encouraging teachers to participate in selecting the appropriate technologies for use in the classroom. Finally, teachers should know how to avoid the most common mistakes of using technology and be able to rectify most other technology-related issues without further assistance.

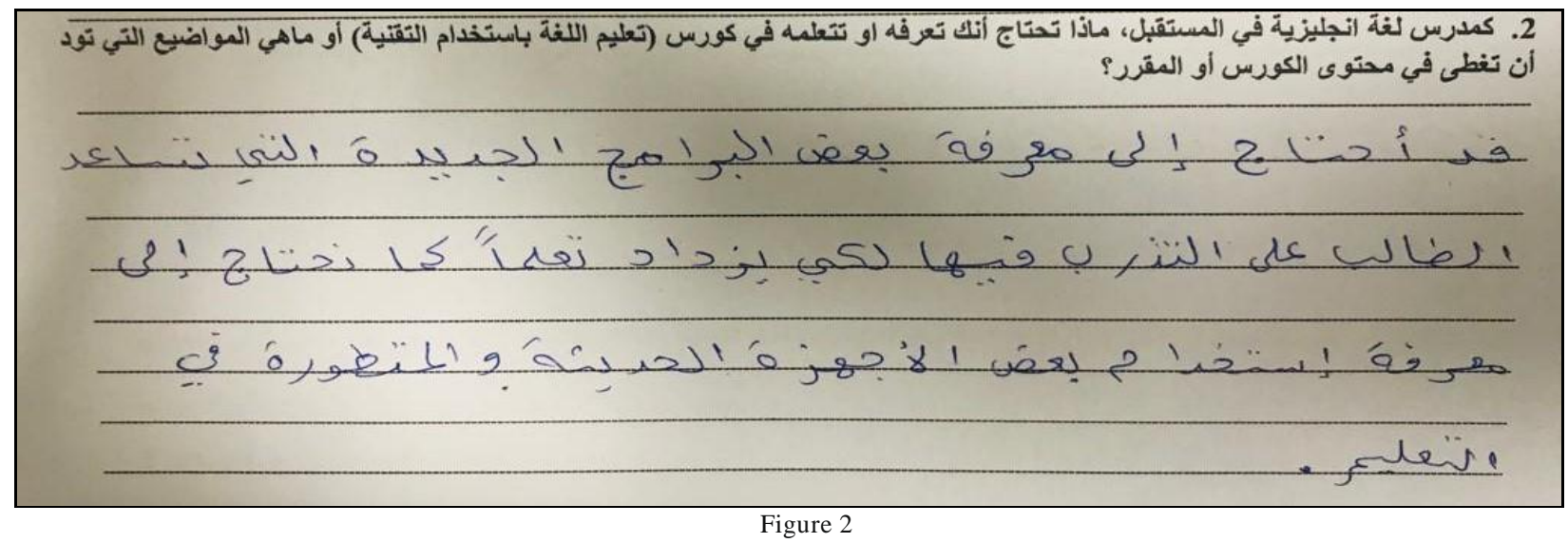

\section{Third Category: Experiences of Pre-service EFL Instructors Before Joining the LL\&T Course}

The third category focuses on the pre-service EFL teacher language learning experiences prior to enrolling in an LL\&T course. Their experience in using technology in learning can be broken down into three main classifications: Common software/applications, social media, and translation software. Almost every pre-service EFL teacher has extensive experience using smartphone application and or common software on tablet/laptop/desktop computer such as Microsoft Office. Also, most of the pre-service EFL teachers have at least some experience using software based on social media platforms, email, and programs for language translation such as Google Translate. Apart from these main categories, pre-service EFL teachers also generally use a variety of electronic media such as websites, YouTube, chat programs, and electronic books, respectively. Figure 3 shows that this respondent indicates that most of his language learning experiences using technology are via mobile phones. The respondent maintains that he was able to improve his speaking and pronunciation skills using a mobile phone. It is worth noting that, in addition to software/applications, hardware is also a factor. Devices vary significantly in form and function. The pre-service EFL teachers experience with various types of devices is part of their experience and therefore influences teaching with technology.

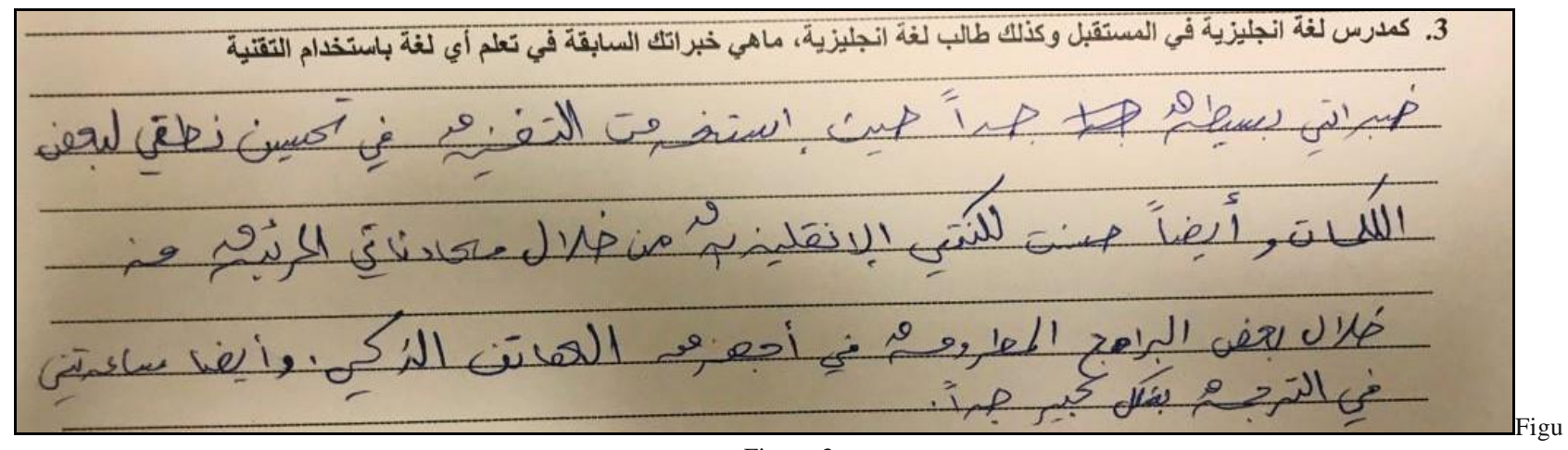

Figure 3 


\section{Fourth Category: Preferred Technologies by Pre-service EFL Instructors in the LL\&T Course}

The subject of the fourth category is the preferred technologies used in the LL\&T course. The data evaluation indicates distinct preferences for certain technologies as more fully set forth below. The participants overwhelmingly favour recording classes. The respondents also show a distinct preference for using computers (laptops/iPads/tablets) to facilitate learning. A significant number of participants utilise educational websites and social media platforms as part of the teaching process. Note that more traditional technologies and methods are still preferred to varying degrees. Many participants favour older technologies such as projectors used in conjunction with traditional face-to-face instruction. This is illustrated as per Figure 4 in which the participant stressed he preferred overhead projectors. He postulated that this older technology saves time and encourages students to pay attention.

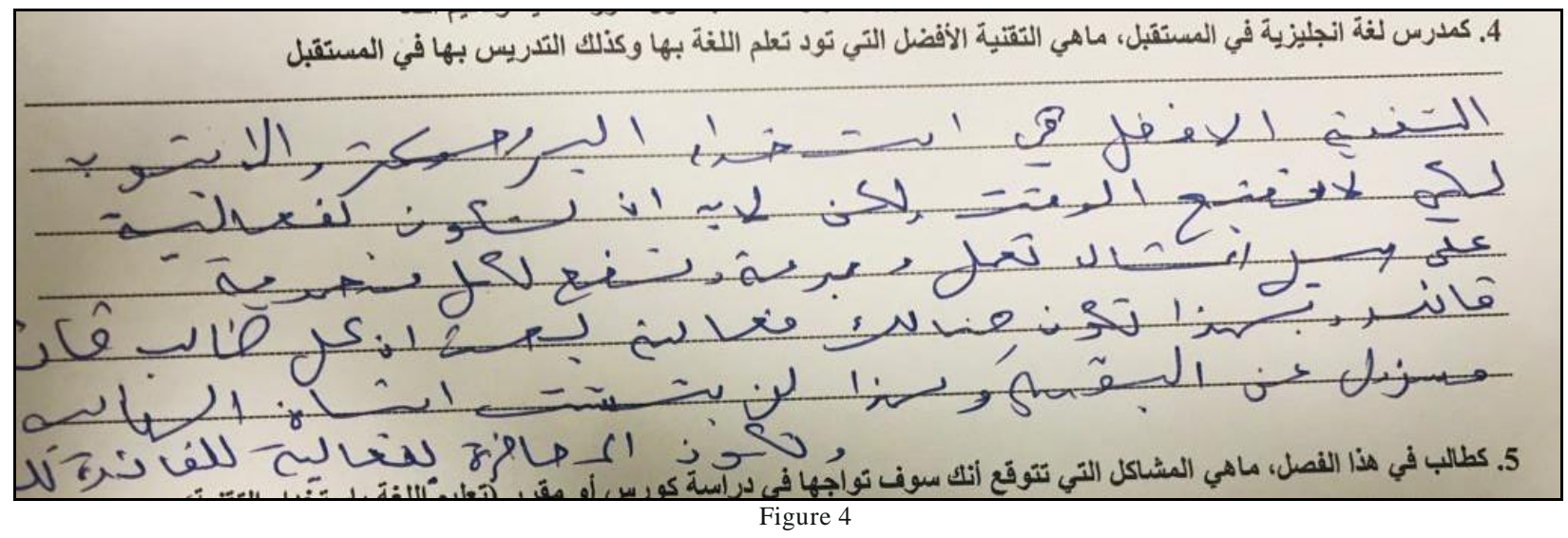

\section{E. Fifth Category: Challenges of Pre-service EFL Instructors in the LL\&T Course}

There are numerous inherent obstacles and challenges the Pre-service EFL teachers must conquer in order to succeed. Of course, as English is the non-native language, a high degree of proficiency in the target language is challenging to maintain. A second major obstacle is being unfamiliar with the instructional technologies used in the classroom. Pre-service EFL teachers oftentimes have little or no control of the technology being used. A related issue is that a particular school may not have the resources to adopt specific technologies. As shown in Figure 5 infra., this respondent expresses concern about using and training on certain devices. He acknowledges that, due to cost considerations, certain tools may not be readily available in the classrooms. Also, teacher/student resistance to the utilization of newer technologies can be a factor. Class motivation may be impacted when the technologies are not embraced by all stakeholders.

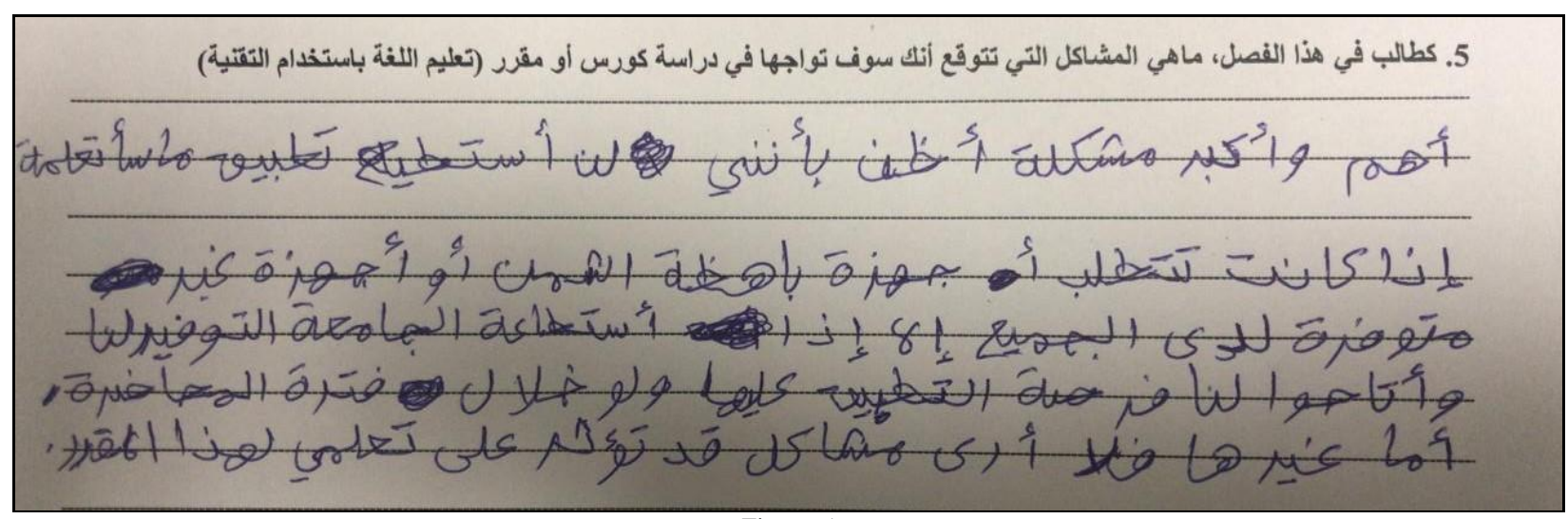

Figure 5

\section{F. Sixth Category: Suggestions of Pre-service EFL Instructors in the LL\&T Course}

The participants in this study were both thorough and thoughtful in their response. They offered many suggestions that are well-reasoned and worth consideration. While the researchers cannot review all of them in this paper, some of the more prevalent recommendations are worth noting. First, many participants advocated for continually updating the course content and recurring training in technologies as they evolve. The second recommendation being that technology usage begin at the lowest levels of instruction so that both students and teachers are comfortable using technologies throughout the coursework. Also, many pre-service EFL teachers suggested that teachers strive to use technology in a way that is enjoyable and that helps motivate the students to 
learn. Another issue raised by pre-service EFL teachers is the degree to which the LL\&T course focuses on the theoretical rather than the practical aspects of using technology. They suggest that the LL\&T course utilize state-ofthe-art labs complete with functioning technologies that will also be used in actual classes when they begin teaching. The final recommendation from the participants concerns the technology itself. Many of them noted that specialized hardware and esoteric software would likely be a problem based on cost and availability. In order to alleviate this potential problem, many of the participants advocated for using commonly available or 'off the shelf' hardware and software. As shown in Figure 6 infra., they expressed enthusiasm for using common devices such as iPads and inexpensive applications available commercially or for free from other educational institutions.

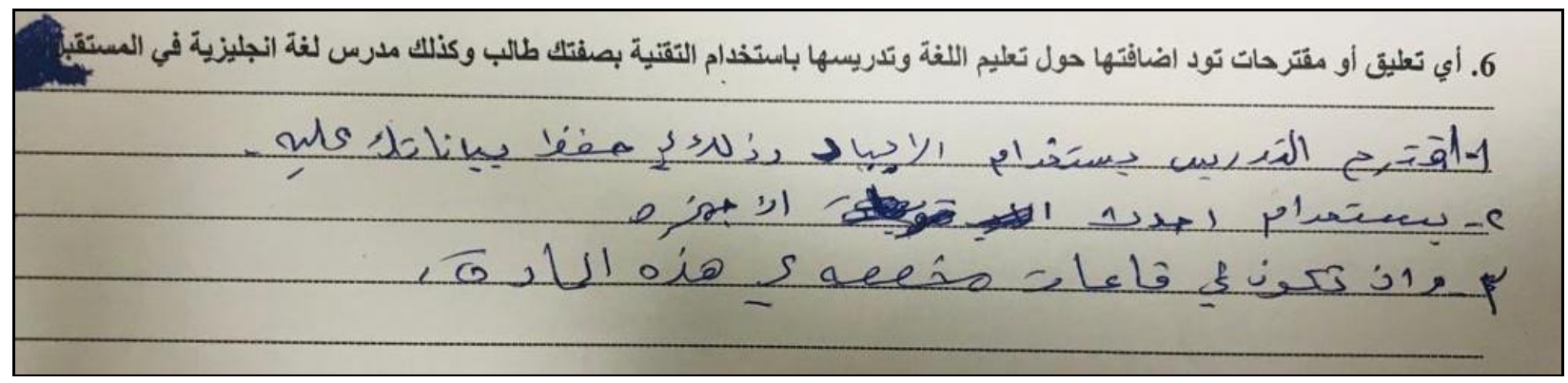

Figure 6

\section{RESUlts DisCUSSION}

\section{A. What Are the Needs and Expectations of Pre-service EFL Instructors in an LL\&T Course?}

The results of the first category of inquiry concerning the needs and expectations of pre-service EFL teachers were instructive. One widespread opinion gleaned from the survey is that the participants believed that the course would be more effective if the material were taught while actually utilising the various technologies in a mock EFL setting. Another common area of concern was training. Many participants were either concerned about, or even actually experienced, learning technology(ies) being implemented without adequate teacher training. Furthermore, the data suggests that many teachers are aware that, to teach using technology, one must be highly proficient in the target language as well as have a thorough understanding of the limitations of the technology being used for teaching purposes. Participants also alluded to other factors in learning effectiveness such as motivation and confidence in utilising technology. Naturally, one would expect those who are well-versed and adequately trained in technology would approach their teaching duties with a higher degree of confidence and competence than those not adequately trained on the technology. However, due to the qualitative nature of this study, this common-sense conclusion cannot be quantitatively proven in this study.

\section{B. Are There Common Preferences for Students and Pre-service Teachers with Respect to Hardware Platforms and Software Applications for Teaching and Learning Processes?}

The results of this study also explore the ways in which prior experiences of both teachers and learners affect the delivery and acquisition of the target language. The evidence suggests that both teachers and students are most comfortable with the types of hardware they have been accustomed to using for non-teaching purposes. For example, many participants reported their preference for using laptop computers, tablet computers, and smartphones. The participants also reported a strong preference for user-friendly software, such as programs easily accessed via internet-based applications that work well across the various hardware platforms. Notwithstanding the apparent enthusiasm for more advanced technologies, the classic tools of education remain popular. Live lectures and simple projectors are all deemed highly effective. It seems that the participants desire a finely balanced combination of classical teaching methods and advanced technology to deliver an effective learning experience.

\section{Challenges \& Suggestions}

The challenges and obstacles both teachers and learners face can be both numerous and daunting. Difficulties range from insufficient knowledge of the relevant vocabulary to a lack of understanding as to the function and operation of the various devices and software packages. It is noteworthy that a statistically significant number of study participants expressed a firm dislike of using technologically advanced devices and programs. Important and valid concerns include the speed with which technologies change, and the cost and logistical requirements for continually updating the educational technologies. This study also attempted to address other effectiveness factors of the technology such as user satisfaction experience value and attractiveness of the technology resources. These are of course difficult to analyze given the qualitative nature of the study, and the subjective nature for factors such as 'enjoyment' and 'attractiveness'. An overriding theme evident in the study is the participant emphasis on training. Clearly, a lack of adequate training is a critical area of concern for many of the study participants. 


\section{A. Themes}

Despite the relatively small sample size of the study, the research indicates three themes or common issues of interest to the majority of the survey participants as more particularly set forth below:

1. Knowledge Base of Pre-Service Teachers

The research indicates that pre-service teachers are very concerned about the preparation and training of aspects of integrating advanced and rapidly evolving technology into teaching programs and individual courses. Incorporating advanced technologies into learning programs can make courses both engaging and highly effective. Conversely, poorly integrated technologies can lead to confusion, frustration, and inefficiency. In sum, the study participants are generally receptive to using technology, so long as they are prepared to use the equipment and systems effectively.

2. Needs of Both Instructors and Students

The 'needs' of both the students and teachers are critical in utilizing technology. Students learn in different ways and are often best served by using different teaching methods. In addition, sometimes technology is a great teaching tool that is effective when used properly. Other times, old-fashioned teaching methods and resources are the most efficient and effective ways of imparting language lessons. Also, there are those all too frequent instances when technology lets teachers down (i.e., the computer screen freezes, or the software crashes). A good teacher must be prepared to overcome such pitfalls of the modern world. In sum, teachers must be flexible to accommodate the students and to succeed in teaching even when the technology fails.

3. Motivation

One of the most critical elements of second language teaching and acquisition is 'motivation'. The interplay between technology-based learning and motivation is a relatively new phenomenon in education. Having both the teacher and the students engaged in the coursework using technology has enormous potential benefits. Prior research shows that this may lead to optimal learning outcomes (Chatel, 2002; de Jong \& Harper, 2005). Technology can be useful in many learning scenarios from grasping abstract theoretical concepts to something as mundane as learning to use a new device or software package. Id. The study also shows that motivation is closely linked to the other two themes in this section. See section i and section ii, supra.

\section{B. Recommendations}

Technology in learning is now part of the educational zeitgeist. Today's teachers are now expected to deliver lessons using the latest in electronic tools and multi-media spread among many different platforms. Some argue that demonstrable technological prowess should be a prerequisite for most all teaching assignments. Even further, some may argue that technology will ultimately render traditional teaching methods and those who utilize them obsolete.

Teachers should keep several issues in mind in the utilization of technologies including:

a) Whether the technology to be used provides an actual benefit over traditional methods;

b) Whether the technology is the most effective and efficient means of delivery;

c) Whether the technology is being used for a constructive purpose or just 'coolness factor';

d) Whether rapidly evolving technology is worth the cost of staying 'current'.

These issues are prevalent in education today and are often difficult to address. The answers to the above are contingent upon a high number of variables, many of which are highly subjective. Teacher attitude and training, as well as student motivation, certainly affect the use of technology. Also, the immutable realities of budgets and resource priorities also are major factors in incorporating technology into education. Pre-service EFL teachers must address these issues along with the many other challenges that are inherent in the teaching profession.

Achieving a balance in technology-based learning can be difficult. Some teachers argue that modern technology is simply unnecessary. Traditional methods have been around for centuries, and have been effective. Those teachers argue that implementing technology is just wasting time and money. This is classic 'If it ain't broke, don't fix it' thinking. Such wisdom is oftentimes the basis for good advice. On the other hand, there are those who embrace technology and want to incorporate same into every aspect of education. They believe that change is inevitable and that teachers must change with the times or become irrelevant. This is the basic 'evolve or perish' theory of existence for which there are clear precedents for following its tenets. Whether the answer is to shun or embrace technology is debatable. Many more argue that the answer lies somewhere between those two extremes. These are issues which educators will be studying and debating for many years to come.

Assuming arguendo that educators continue to use technology at an increasing rate, assessing the technology will be increasingly difficult. There are so many different platforms (i.e., smartphones, tablet computers, laptop computers) spanning many types of programs (i.e., internet-based, commercial software packages, etc.) that keeping up with the range of technologies is daunting. Moreover, each platform and program evolves and changes at astonishing rates. Some platforms/programs will suddenly cease to exist and be replaced by new ones. One might reasonably doubt teachers' abilities to research, analyze and evaluate teaching technologies and methods in such a rapidly changing environment. Yet one cannot reasonably just ignore the issue. Technology can help motivate students. Incorporating technology into LL\&T courses can support language learning. One could not reasonably turn a blind eye to such potential improvements to education. It seems that the most reasonable course of action to 
make an effort, whether at an individual or collaborative level (i.e., interscholastic cooperatives) to continually evaluate technologies in education.

\section{CONCLUSION}

This article presents and discusses six major issues concerning technologies in LL\&T courses for pre-service EFL teachers. The results raise the legitimate concerns and issues which pre-service EFL teachers face about technology in the LL\&T course. Their collective concerns and recommendations can help policy-makers design more effective course objectives and program learning outcomes. LL\&T course materials will focus on technologies that instructors need and expect to use in classrooms, rather than technologies that policy-makers and training program designers think are useful. Including pre-service EFL instructor expectations and needs in course design will help motivate instructors and ultimately benefit the students. Understanding the previous instructor experiences about using technology will help trainers and policy-makers introduce technologies that are useful and appropriate. Implementing the preferred technologies by pre-service EFL instructors will reduce their anxiety in classes and encourage them to use these technologies in their classrooms in the future. The results of this paper also demonstrate the necessity for careful evaluation and training that should precede any LL\&T course. This initiative will help policy-makers and program designers prevent difficulties in the course thus leading to more favourable outcomes. Much valuable information is available directly from the end users. As evidenced by the response to this survey and research results, the LL\&T instructors have an 'in the trenches' view of the educational environment and have good advice for evaluating and implementing technology.

\section{REFERENCES}

[1] Alhamami, M. (2018). Directions to digital language learning and teaching. Createspace, Amazon.com. Link http://a.co/d/8fSKRyL

[2] Baföz, T. (2016). Pre-service EFL teachers attitudes' towards language learning through social media. Procedia-Social and Behavioral Sciences, 232, 430-438.

[3] Chatel, R. G. (2002). New technology, new literacy: Creating a bridge for English language learners. The New England Reading Association Journal, 38(3), 45-49.

[4] de Jong, E. J., \& Harper, C. A. (2005). Preparing mainstream teachers for English-language learners: Is being a good teacher good enough? Teacher Education Quarterly, 32(2), 101-124

[5] Dong, Y., Chai, C. S., Sang, G.-Y., Koh, H. L., \& Tsai, C.-C. (2015). Exploring the profiles and interplays of pre-service and in-service teachers' Technological Pedagogical Content Knowledge (TPACK) in China. Educational Technology \& Society, 18(1), 158-169

[6] Firat, M., \& Serpil, H. (2017). Comparing the internet usage of pre-service language teachers with teachers of other subjects: Distance learning vs. on-campus learning. Profile Issues in Teachers Professional Development, 19(1), 55-72.

[7] Koçoğlu, Z. (2009). Exploring the technological pedagogical content knowledge of pre-service teachers in language education. Procedia Social and Behavioral Sciences, 1, 2734-2737.

[8] Long, M. H. (Ed.). (2005). Second language needs analysis. Cambridge, UK: Cambridge University Press.

[9] Merç, A. (2015). Using Technology in the Classroom: A Study with Turkish Pre-Service EFL Teachers. Turkish Online Journal of Educational Technology-TOJET, 14(2), 229-240.

[10] Satar, H. M., \& Akcan, S. (2018). Pre-service EFL teachers' online participation, interaction, and social presence. Language Learning \& Technology, 22(1), 157-183.

[11] Yüksel, G., \& Kavanoz, S. (2011). In search of pre-service EFL certificate teachers' attitudes towards technology. Procedia Computer Science, 3, 666-671.

[12] Zyad, H. (2016). Pre-Service training and ICT implementation in the classroom: ELT teachers' perceptions. International Journal of Education and Development using Information and Communication Technology, 12(3), 4-18.

\section{APPENDIX. QUESTIONNAIRE ITEMS TRANSLATION}

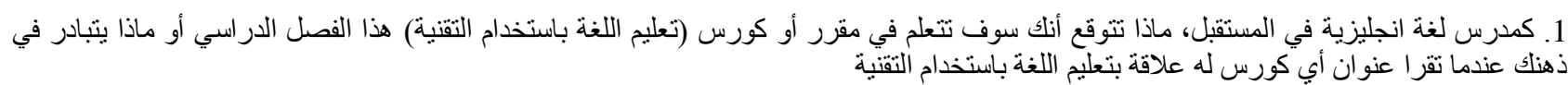

1. As an English language teacher in the future, what will you expect to learn in language learning and technology course this semester? Alternatively, what comes to your mind when you read a course his title is related to language learning using technology?

2. كمدرى الكورس لغة أنجليزية في المستقبل، ماذا تحتاج أنك تعرفه او تتعلمه في كورس (تعليم اللغة باستخدام التقنية) أو ماهي المواضيع التي تود أن تغطى في

2. As an English language teacher in the future, what do you need to know and learn in language learning and technology course? Alternatively, what topics that you would like to be covered in the content of the course 3. كمدرس لغة انجليزية في المستقبل وكذلك طالب لغة انجليزية، ماهي خبر اتكا السابقة في تعلم أي لغة باستخدام التقنية

3. As an English language teacher in the future and also English language learner, what are your previous experiences in learning languages using technologies?

$$
\text { 4. كمدرس لغة انجليزية في المستقبل، ماهي التقنية الأفضل التي تود تعلم اللغة بها وكذلك التذريس بها في المستقبل }
$$


4. As an English language teacher in the future, what are the best technologies that you would like to learn technology with and to teach language with in the future?

$$
\text { 5. كطالب في هذا الفصل، ماهي المشاكل التي تتوقع أنك سوف تو اجها في دراسة كورس أو مقرر (تعليم اللغة باستخدام التقنية) }
$$

5. As a student this semester, what challenges that you might face while studying in language learning and technology

course?

$$
\text { 6. أي تعليق أو مقترحات تود اضافتها حول تعليم اللغة وتدريسها باستخدام التقنية بصفتك طالب وكذلك مدرس لغة انجليزية في المستقبل، }
$$

6. Any comments and suggestions that you would like to add regarding learning and teaching languages using technologies as a current English instructor and future English language instructor.

Munassir Alhamami is an assistant professor at the Faculty of Languages and Translation at King Khalid University, Saudi Arabia. He received his MA degree from Trinity Western University, Canada. He received the PhD degree from University of Hawai' $i$ at Manoa, USA. His main interests include the effectiveness of language learners' beliefs, online language learning, English for specific purposes, and mixed methods research in applied linguistics.

Hassan Sean Costello completed his undergraduate studies at George Mason University. He obtained an MA in Applied Linguistics from King Khalid University. Hassan started his international TESOL career in the Kingdom of Saudi Arabia after moving from Washington, D.C. in 2013. He teaches a number of language skills courses in the English department at the Faculty of Languages and Translation, King Khalid University, Abha, Saudi Arabia. His research interests include the teaching-learning of academic writing. Hassan is also the Copy Editor for the King Khalid University Website (http://kku.edu.sa/en) and the Digital Ambassador for the Faculty of Languages and Translation (http://flt.kku.edu.sa/en). 